\title{
Research Paper \\ Premarital Education Program Based on Premarital Interpersonal Choices and Knowledge Program on Idealistic Marital Expectation in Single Students
}

\author{
*Gholamreza Rajabi ${ }^{1}$, Ghodratollah Abbasi ${ }^{2}$, Mansour Sudani ${ }^{3}$, Khaled Aslani ${ }^{4}$
}

\begin{abstract}
1- PhD of Psychology, Professor, Department of Counselling, Faculty of Education and Psychology, Shahid Chamran University of Ahvaz, Ahvaz, Iran. 2- PhD of Counseling, Assistant Professor, Department of Psychology, Faculty of Humanities, Sari Branch, Islamic Azad University, Sari, Iran.

3- PhD of Family Counseling, Associate Professor, Department of Counselling, Faculty of Education and Psychology, Shahid Chamran University of Ahvaz, Ahvaz, Iran. 4- PhD of Counseling, Associate Professor, Department of Counselling, Faculty of Education and Psychology, Shahid Chamran University of Ahvaz, Ahvaz, Iran.
\end{abstract}

Citrat on: Rajabi Gh, Abbasi Gh, Sudani M, Aslani Kh. [Premarital Education Program Based on Premarital Interpersonal Choices and Knowledge Program on Idealistic Marital Expectation in Single Students (Persian)]. Iranian Journal of Psychiatry and Clinical Psychology. 2016; 22(3):212-221. https://doi.org/10.18869/acadpub.ijpcp.22.3.212

https://doi.org/10.18869/acadpub.ijpcp.22.3.212

Received: 29 May 2015

Accepted: 04 Apr. 2016

Keywords:

Premarital educa-

tion, Premarital interpersonal choice and knowledge program, Idealistic marital expectation

\section{A B STRACT}

Objectives The aim of this study was to examine the effectiveness of premarital education based on interpersonal choice and knowledge program in reducing idealistic marital expectation.

Methods This research was a experimental design with pretest-posttest and follow-up with the control group. From this population, 38 volunteer single students of universities of Ahvaz city were selected on the basis of 1 standard deviation higher of the mean of idealistic marital expectation subscale and were assigned randomly to experiment group $(n=19)$ and control group $(n=19)$. The experiment group was given a premarital interpersonal choice and knowledge program of 9 sessions, twice a week for 90 minutes. Results The results of analysis of variance repeated measures showed that the premarital interpersonal choice and knowledge program training has led to a reduction in idealistic marital expectation in the experimental group than in the control group at posttest and follow-up.

Conclusion Our results showed that the premarital interpersonal choice and knowledge program is a suitable method for reducing the idealistic marital expectation singles. 


\title{
آموزش قبل از ازدواج به شيوه برنامه آتاهى و انتخابهایى بينفردى بر انتظارات زناشويى ايدهآل

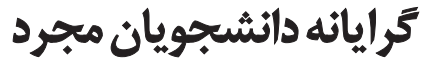

\author{
"غلامرضا رجبى'، قدرتالله عباسى'، منصور سودانى"، خالد اصلانى"

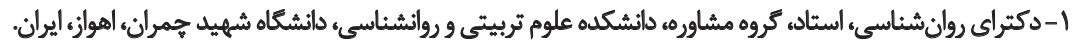

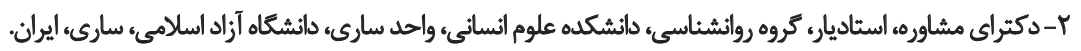

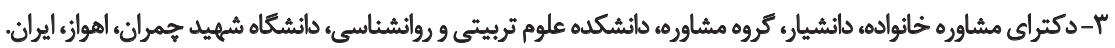

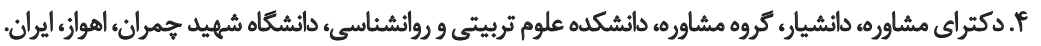

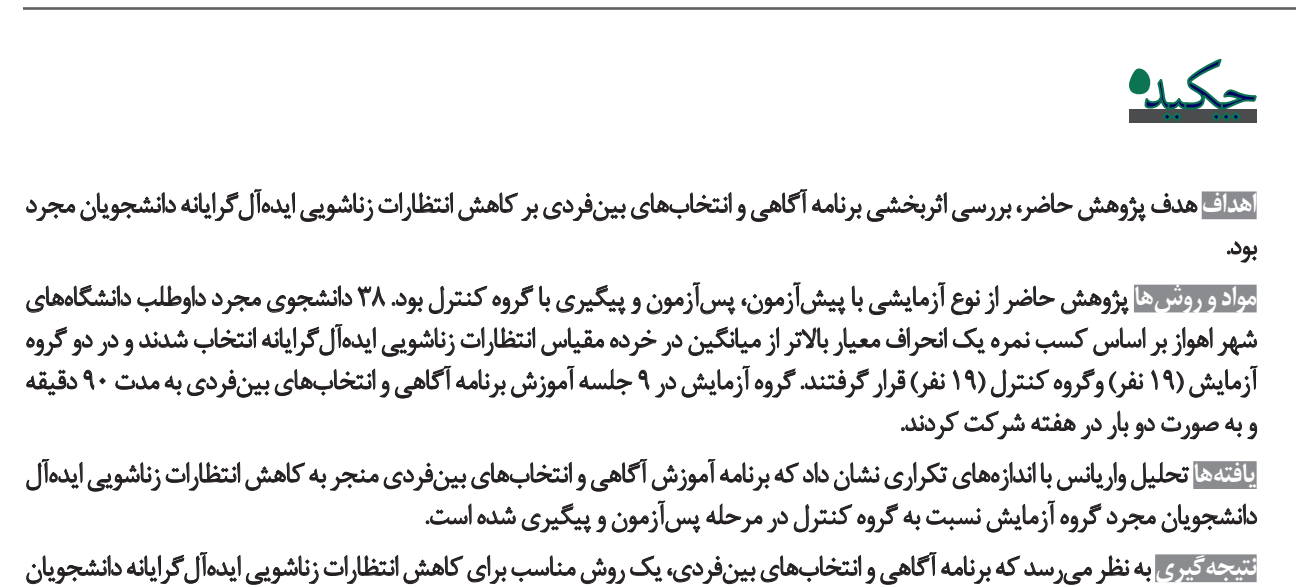

مجرد باششد.

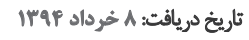
تاريخ بذيرش: 19 فروردين هونه

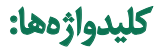

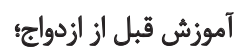

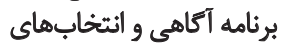

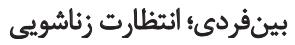

تعامل بين افراد و تعدادى از عوامل مثل خانواده مبدأ، باورهاى

dalo

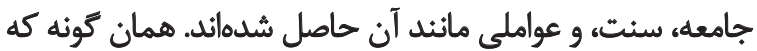

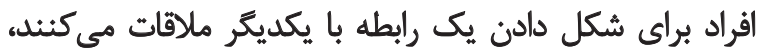

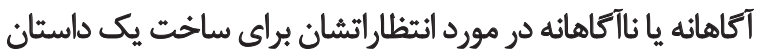

يكيار جه و منسجم كفتلكو مي كنيند [بآ]

اغلب نويسندكان انتظار از ازدواج را به عنوان يك فرايند

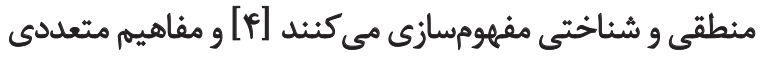

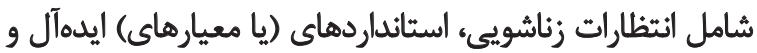

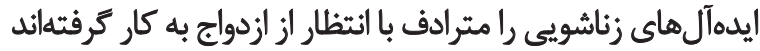

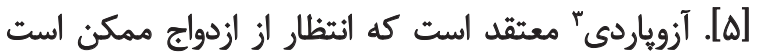

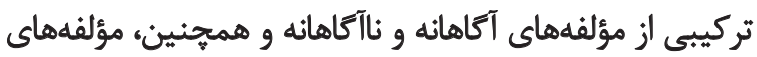

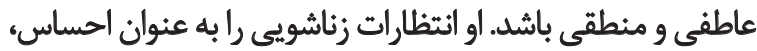

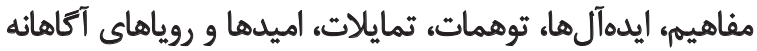

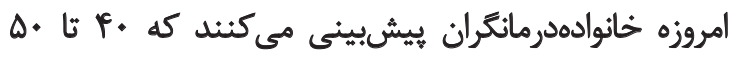

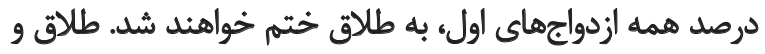

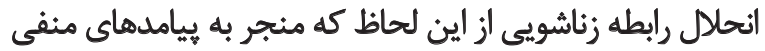

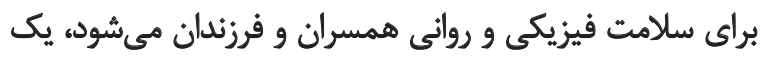

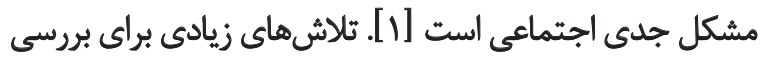

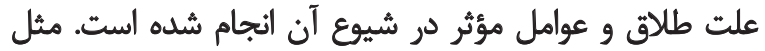

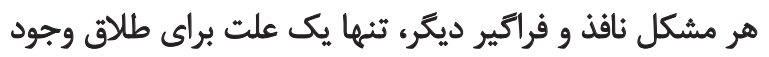

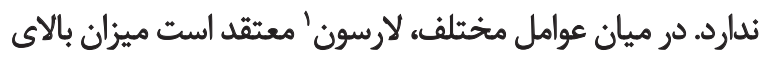

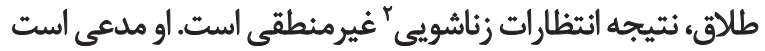

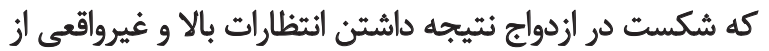

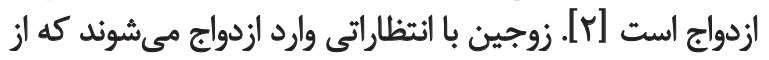

\section{Marital expectation \\ 1. Larson}

\section{-}

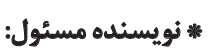

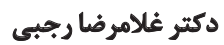

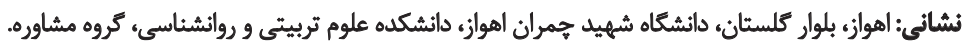
تلغن: rajabireza@scu.ac.ir يست الكترونيكي: 
اين ايدهآل ها يا انتظارات زناشويى ايدهآل برآورده نشونده احتمالاً

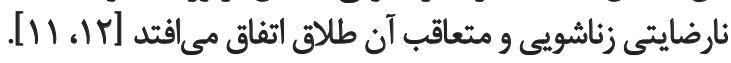
به طور كلى، يك توافق كسترده وجود دارد مبنى بر اين كه

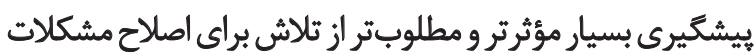

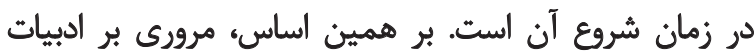

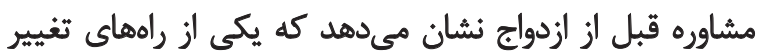

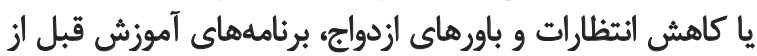

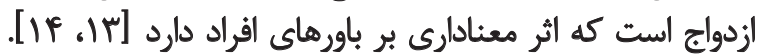

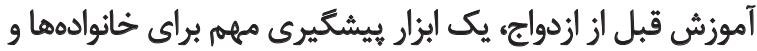

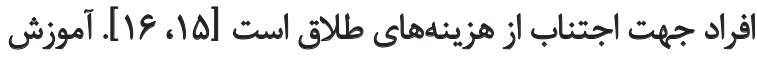

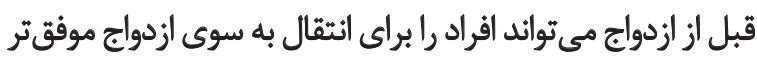

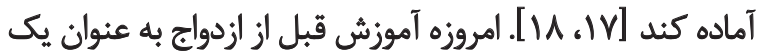

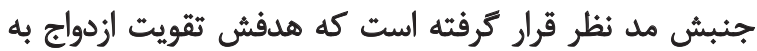

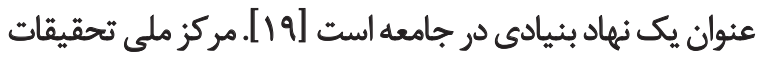

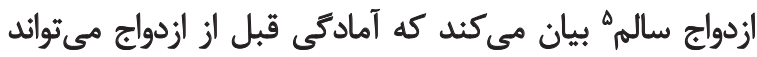

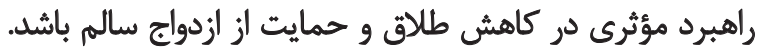

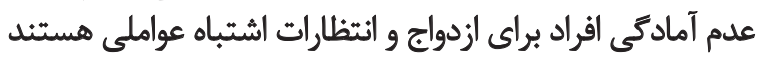

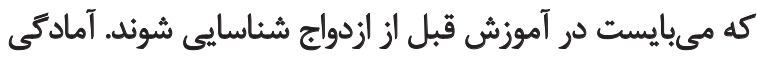

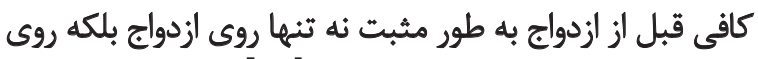

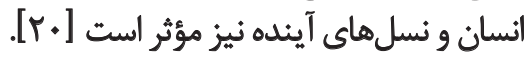

يكى از برنامههايي كه در زمينه آموزش قبل از ازدواج استفاده

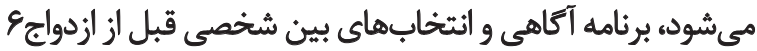
(PICK)

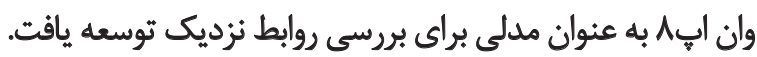

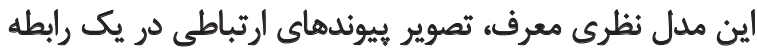

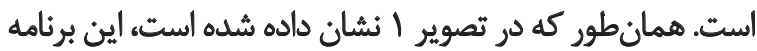

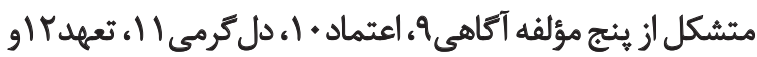

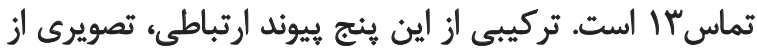
احساس كلى در يك رابطه و اطلاعات معنادارى در درئ مورد احساس

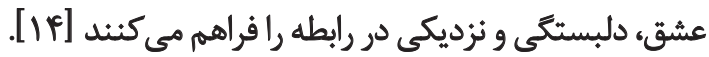
برنامه PICK اين ينج مؤلفه ارتباطى را در دو دو بخش دانس دانش

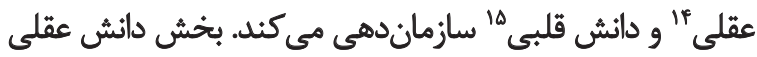

5. National Healthy Marriage Research Center

6. Premarital Interpersonal Choices and Knowledge (PICK)

7. Relationship attachment model

8. Van Epp

9. Knowledge

10. Trust

11. Reliance

12. Commitment

13. Touch

14. Head

15. Heart
و ناآكاهانه يك شخص در مورد ازدواج آينده تعريف مى كند

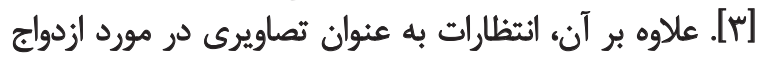

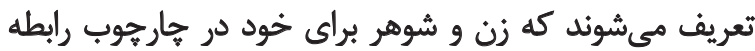

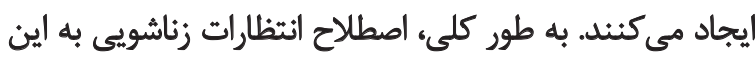

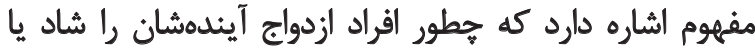

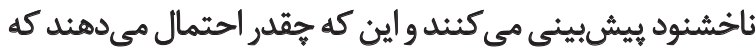

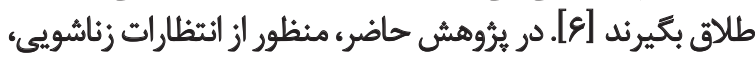
انتظارات ايدهآل و غيرواقعى از ازدواج است. مرورى برادبيات يرؤشى نشان ميى دهد كه يكى ازخطرناكترين

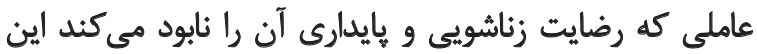

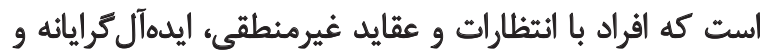

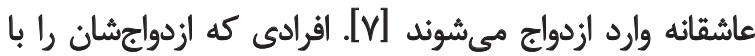

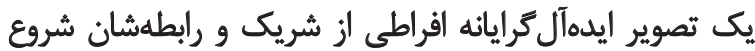

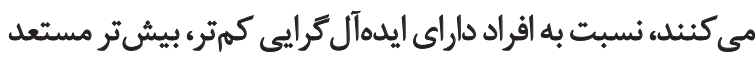

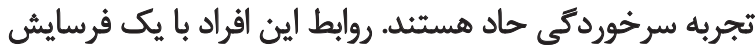

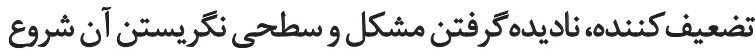

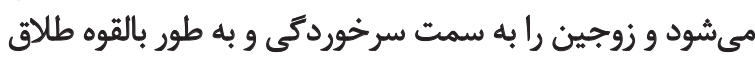

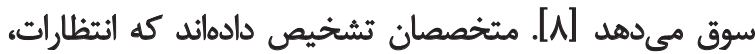

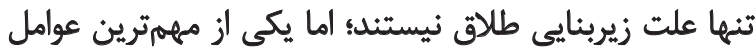

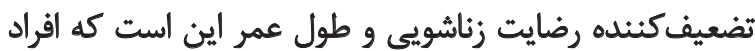

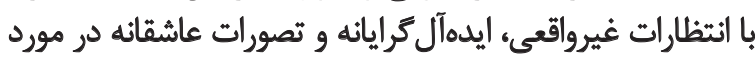

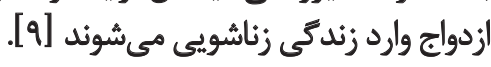

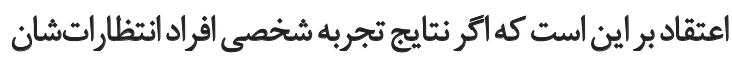

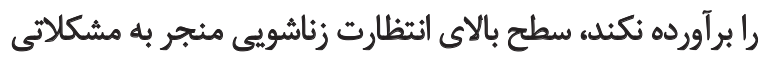

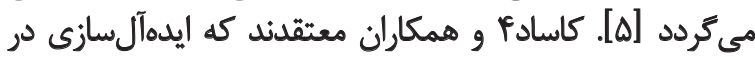

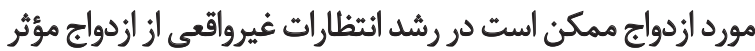

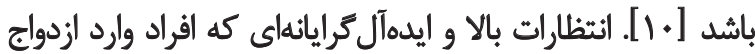

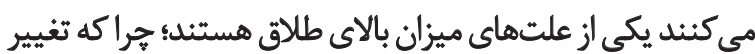

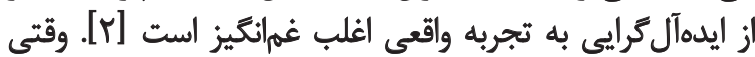

\section{Casad}

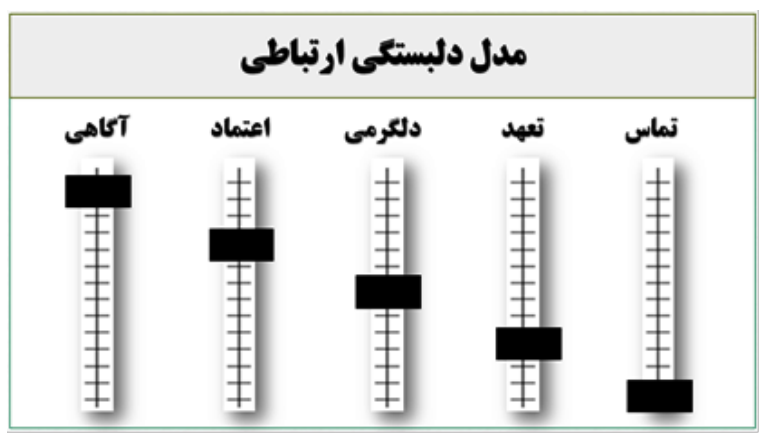

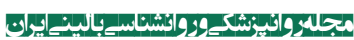

تصوير ا. مليل تصويرى دلبستكى ارثباطى (MAR). 


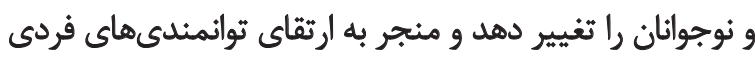

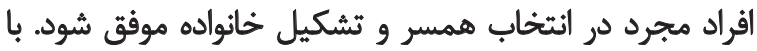

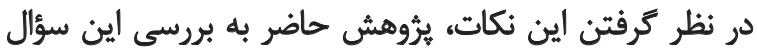

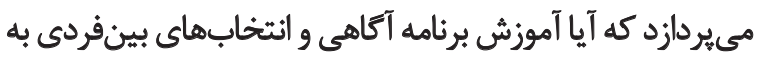

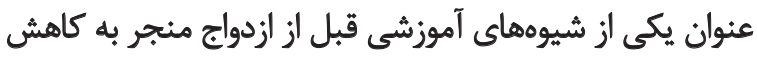

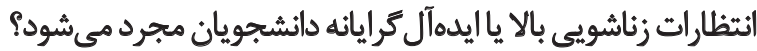

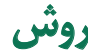

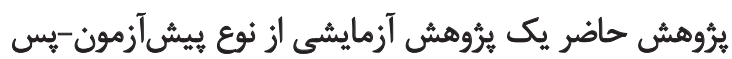

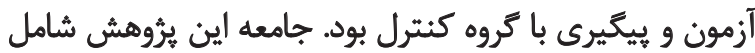

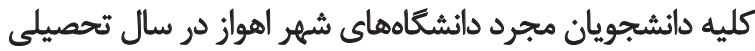

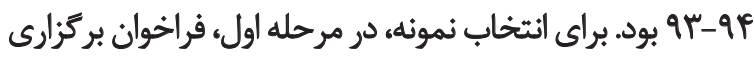

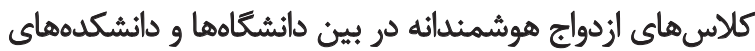

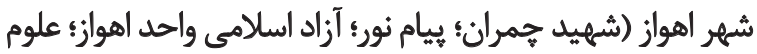

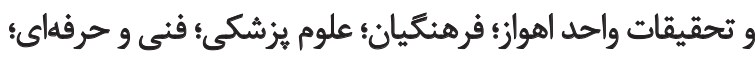
علمى كاربردى كارون؛ و غيرانتفاعى رهنما) منتشر شد. فئرئ

در مرحله دوم، از بين كليه افراد مجردى كه در اين فراخوان

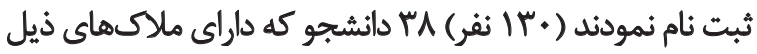

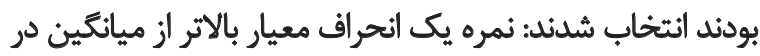

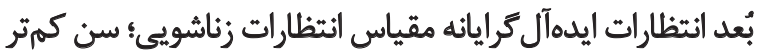

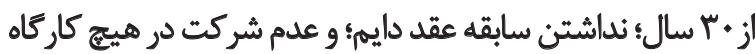

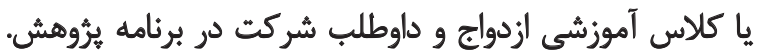

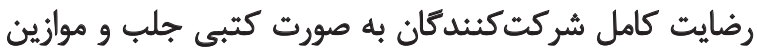

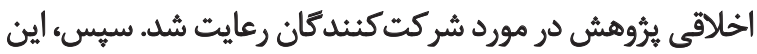

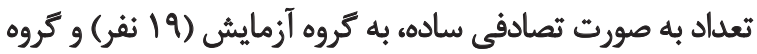
كنترل (19 نفر) اختصاص داده شدند بند

براى ارزيابى انتظارات زناشويى ايدآل ترايانه، از مقياس

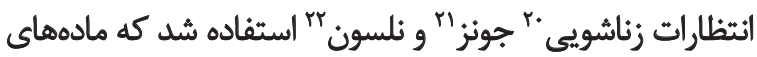

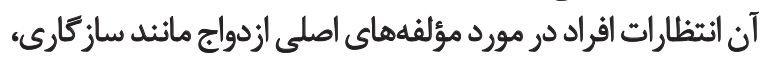

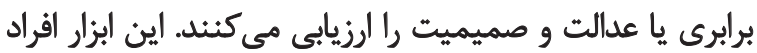

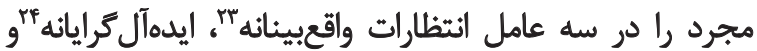

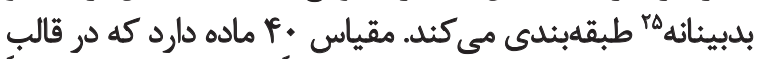

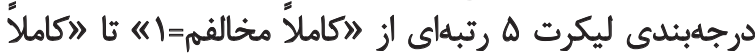

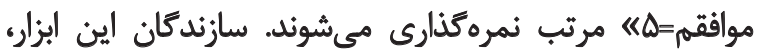

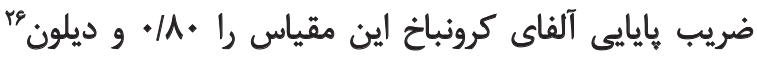

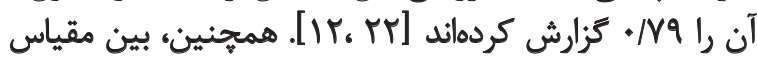

20. The Marriage Expectation Scale

21. Jones

22. Nelson

23. Realistic

24. Idealistic

25. Pessimistic

26. Dillon
به دانش و شناخت دقيق و عميق به دست آماده از شريك يا نامزد

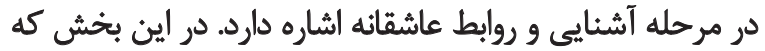

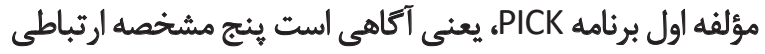

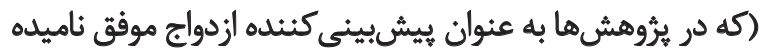

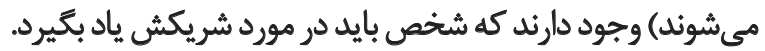

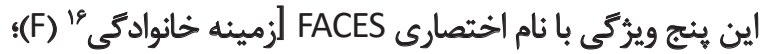

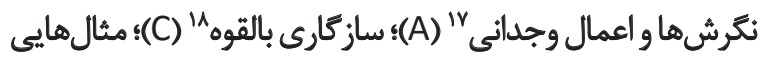

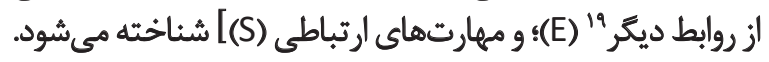

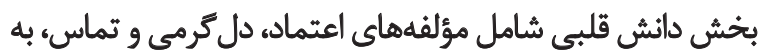

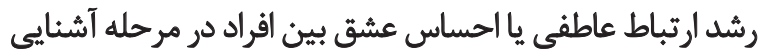

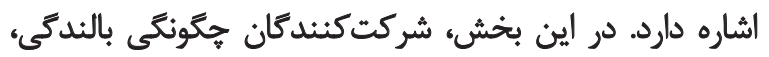

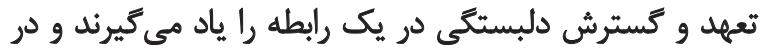

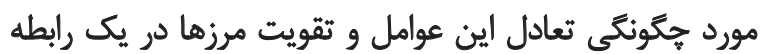

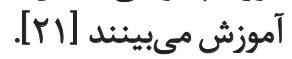

به طور كلى، اين برنامه مرور جامع و كاملى از زمينههائ مهايم

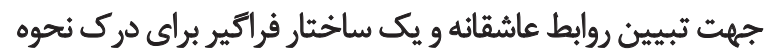

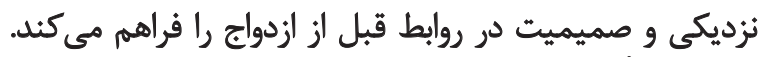

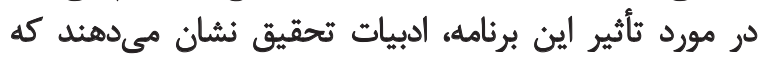

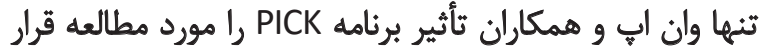

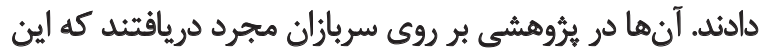

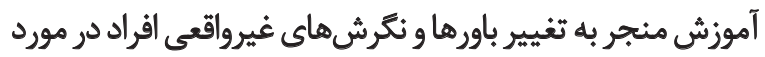

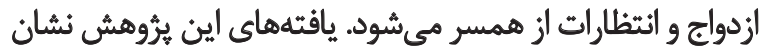

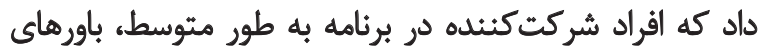

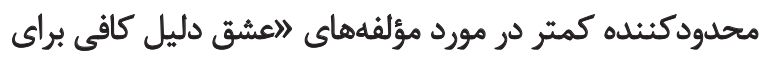

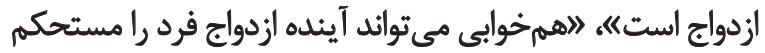

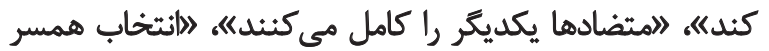

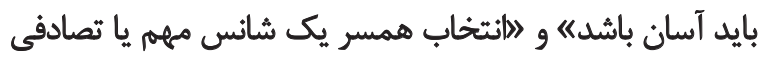

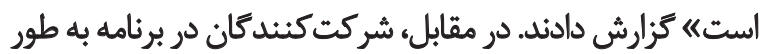

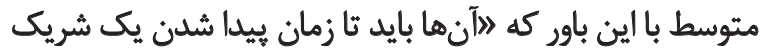

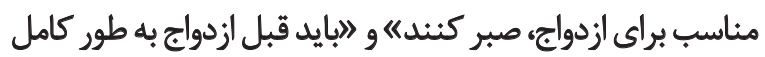

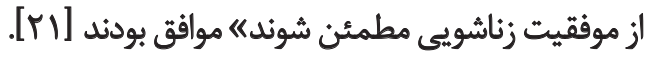

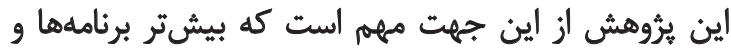

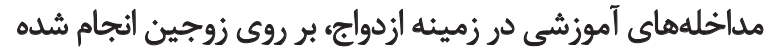

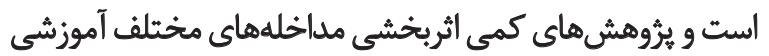

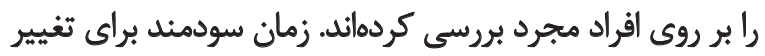

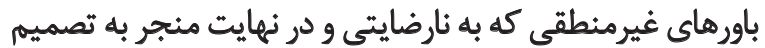

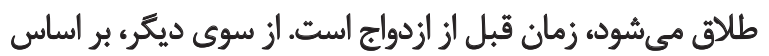

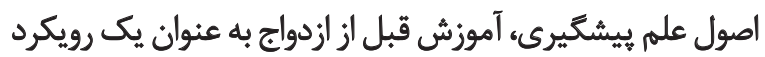

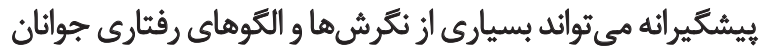

16. Family background

17. Attitudes and actions of the conscience

18. Compatibility

19. Examples of other relationships 
طلاق و كفتكًو در مورد مدل دلبستكي ارتباطي و نحوه كسب دانش عقلى و قلبى خاتمه يافت.

جلسه دوم: آموزش كسب دانش عقلى از طريق آنسئ آشنايى با

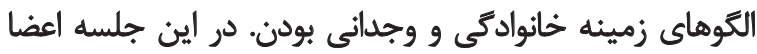

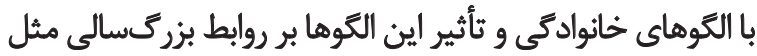

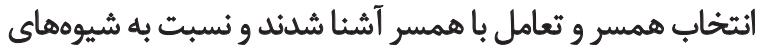

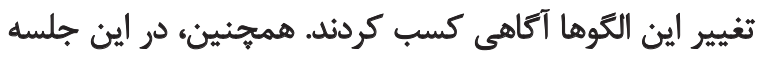

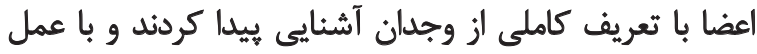
نظارت بر خود و عمل اتخاذ ديدگًاه وجدانى آشنا شدند.

جلسه سوم: آموزش كسب دانش عقلى از طريق درك ساز كارى

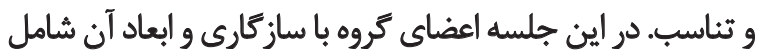

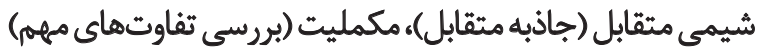

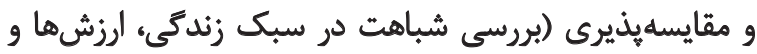
شخصيت) آشنا شدند.

جلسه جهارم: آموزش كسب دانش عقلى از طريق شناخت

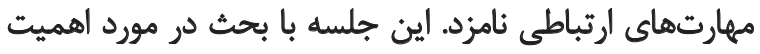

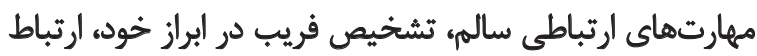

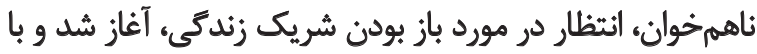

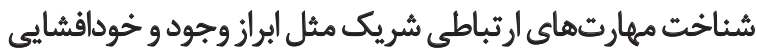

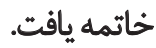

جلسه هنجم: آموزش كسب دانش قلبى از طريق آتاهى از

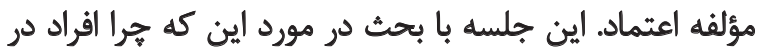

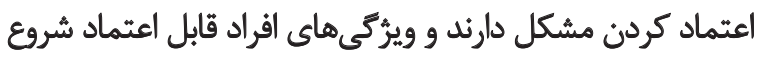

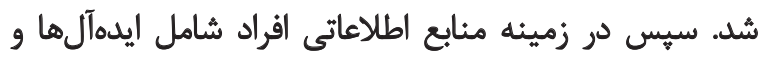
تداعىها به افراد آموزش داده شد.

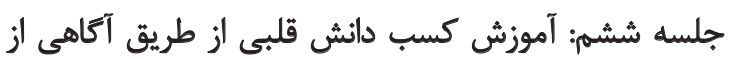

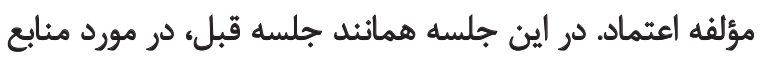

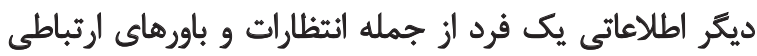

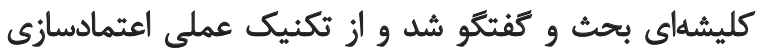

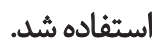

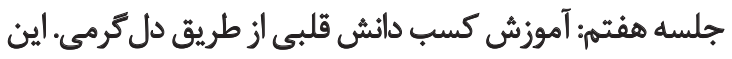

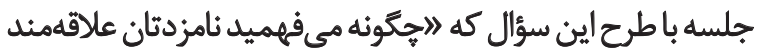

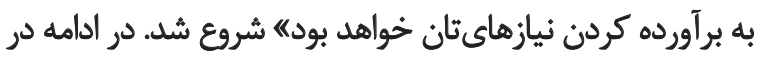

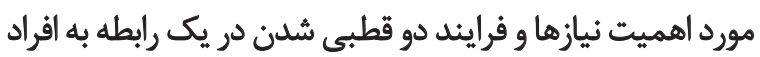

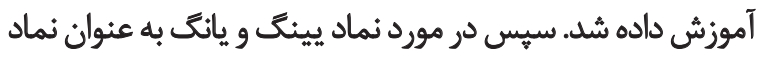

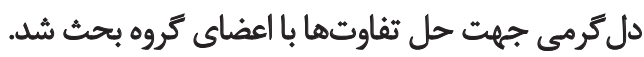

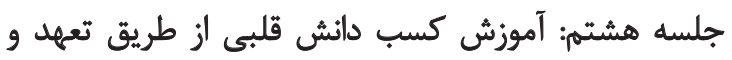

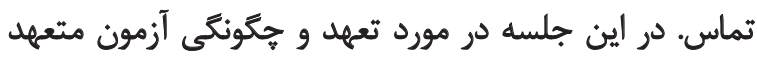

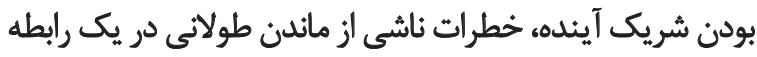

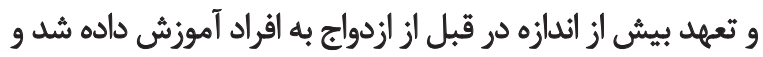

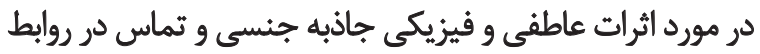

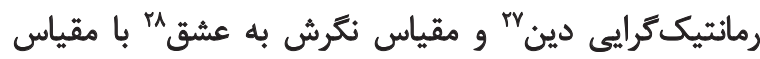

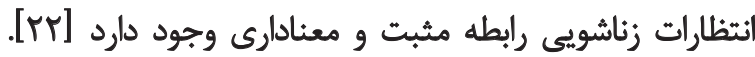

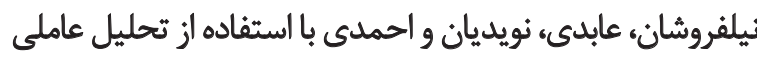

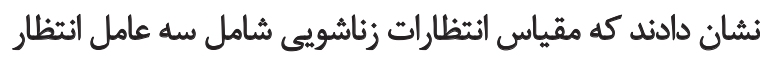

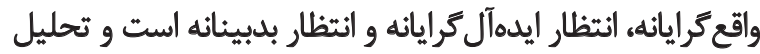

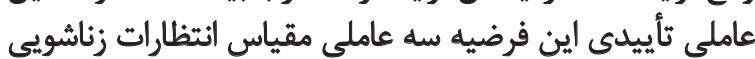

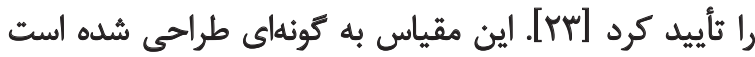

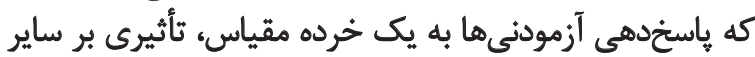

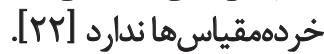

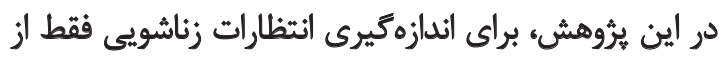

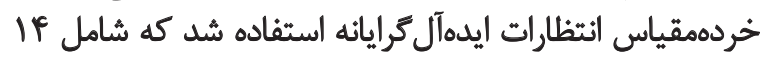

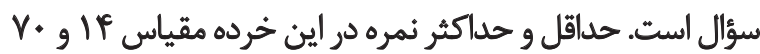

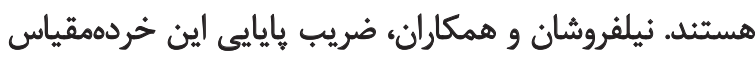

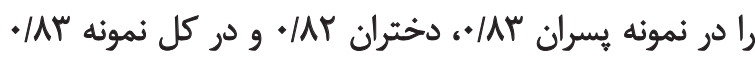

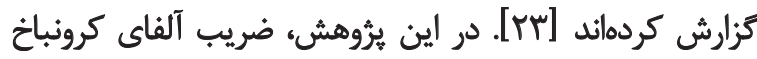

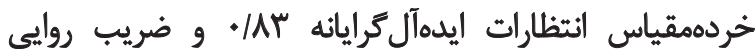

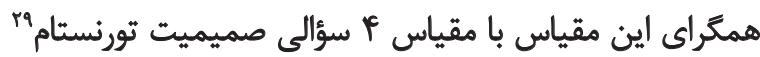

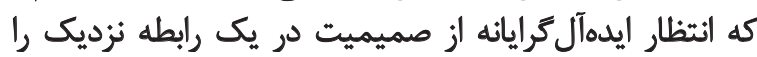

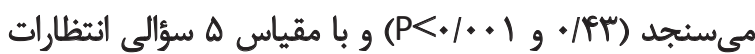

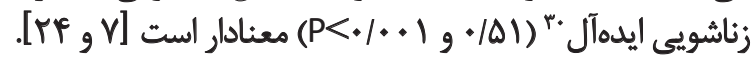
يس از تعيين نمونه مورد بررسي، از كليه دانشجويان منتخب داني

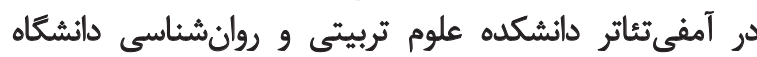

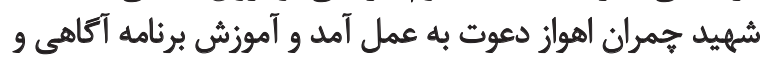

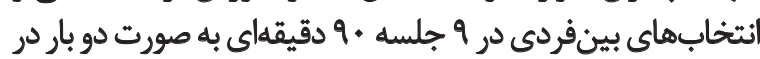

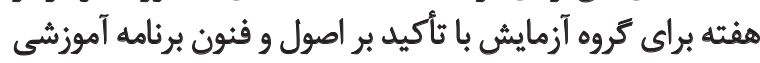

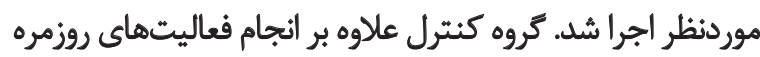

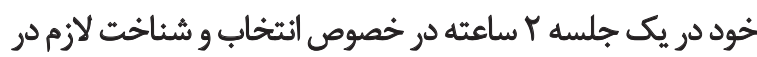

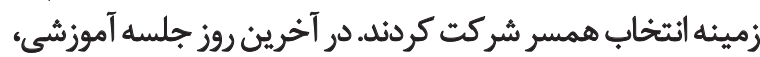

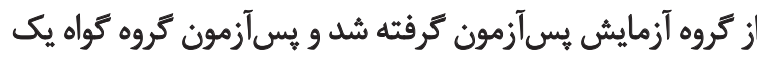

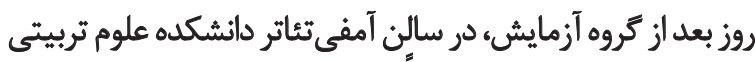

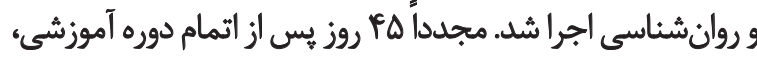

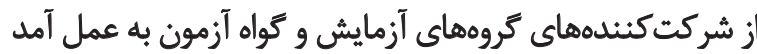

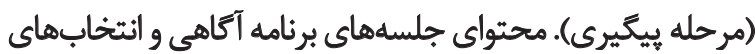

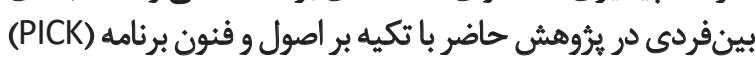

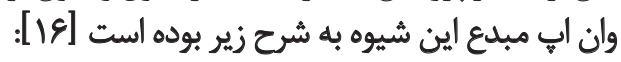

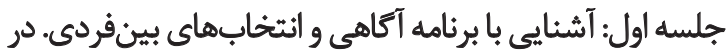

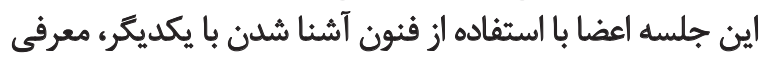

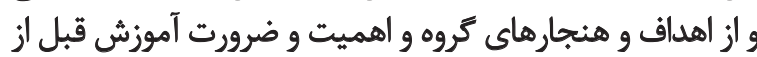

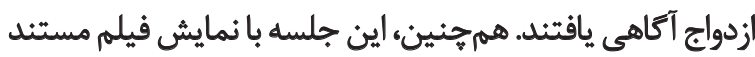

27. The Dean Romanticism Scale

28. Love Attitudes Scale

29. Tornstam intimacy scale

30. ideal martial expectations scale 
همانطور كه در جدول شماره ا ملاحظه مىشود، هيانكين

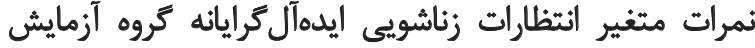

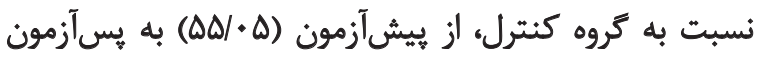

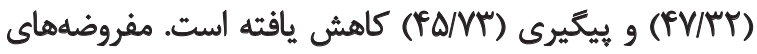

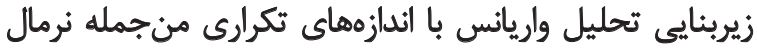

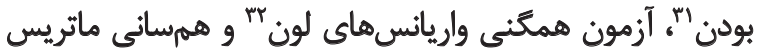

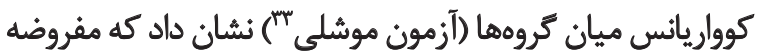

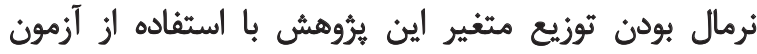

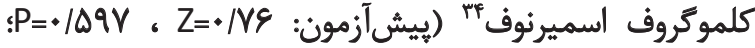
يسآزمون:

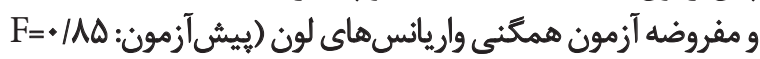

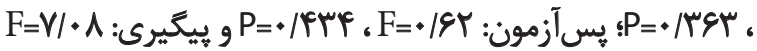

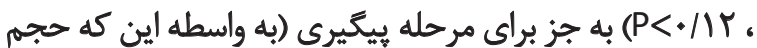

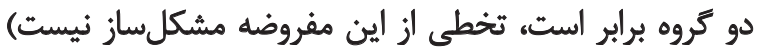

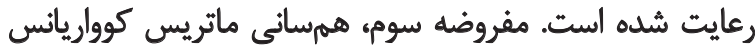

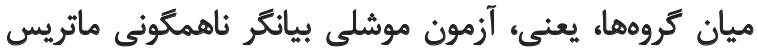

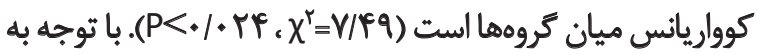

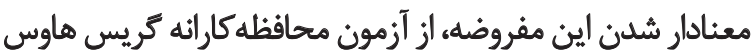

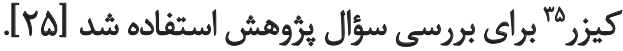
براساس مندرجات جدول شماره r' Fشاهده شده عامل

31. Normality

32. Levene'shomogeneity of variances test

33. Mauchlys test

34. Kolmogorov-Smirnov normality test

35. Greenhouse-Geisser Test Spherecity
قبل از ازدواج بحث شد. در اين جلسه به افراد بينشهاي لازم در مورد نترش و انتظارات افراد در مورد رضايت جنسى اردائه شد. جلسه نههم: مرور مفاهيم اصلى و اجراى يسآزمون. ضمن

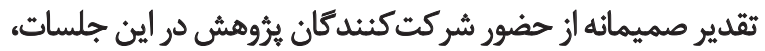

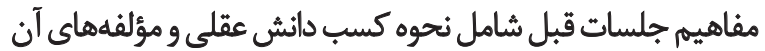

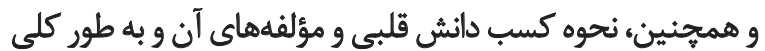

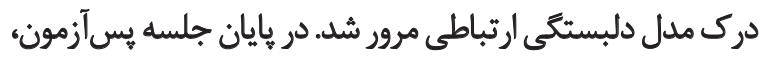

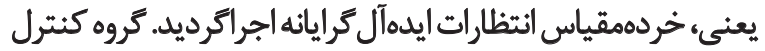

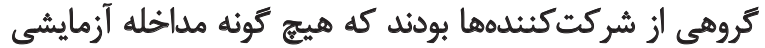

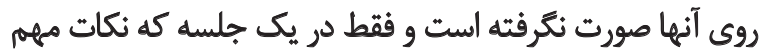

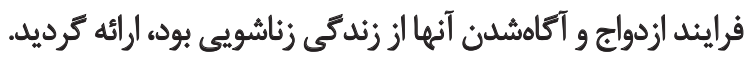

ياقتهما

ميانكين و انحراف معيار سن شركت كنندهها در كروه آموزش

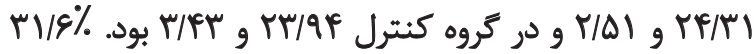

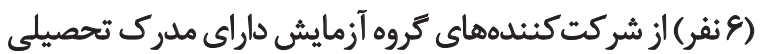

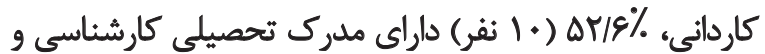

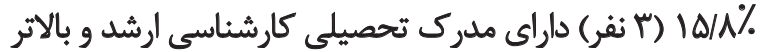

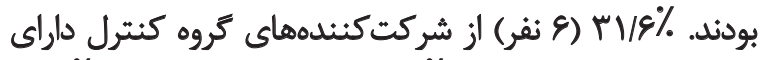

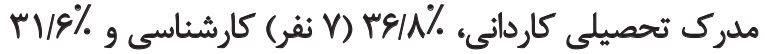
(ب نفر) كارشناسى ارشد و بالاتر بودند.

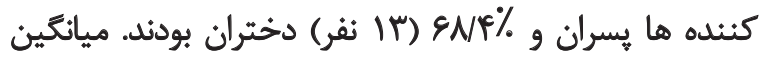

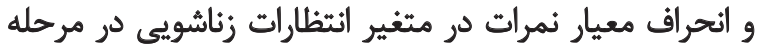

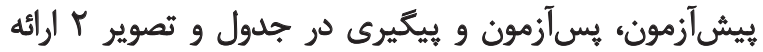
شده است.

جدول ا.ميانكين و انحراف معيار نمرات متغير انتظارات زئاشويى ايدهآلكرايائه در مرحله بيش آزمون، بسآزمون و بيكيرى. ييش أزمون ميانكين ( انحراف معيار) يس آزمون ميانكين ( انحراف معيار) بيكيرى ميانكين ( انحراف معيار)

\begin{tabular}{|c|c|c|c|}
\hline$F \Delta / M^{\top}\left(N{ }^{\top} \Delta\right)$ & $F V / r T(1 . / I I)$ & $\Delta \Delta /+\Delta(V / r \Delta)$ & أزمايش \\
\hline$\Delta F / M(F / F \Delta)$ & $\triangle \Delta / F(Y / \Delta \Delta)$ & $\Delta F / A F(\Delta / 1))$ & كتترل \\
\hline
\end{tabular}

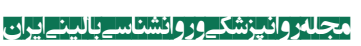

جدول r. نتايج تحليل واريانس باxY با اندازهيرىهاى مكرر بر روى مراحل سهكانه مداخله آموزشي بر كاهش انتظارات زناشويى ايدهآل كرايانه با توجه به كروهها

\begin{tabular}{|c|c|c|c|c|c|}
\hline سطح معنادارى & $F$ & ميانكين مجموع & آزازى & مجذمورات مجنو & منبع تغييرات \\
\hline \multirow[t]{2}{*}{$<+1++1$} & $|V| \cdot 1$ & $|m| m \mid$ & 1 & Imerk & يين أزمودنى ها: كروه \\
\hline & & $V N+9$ & re & rAIIVF. & آزمودنىهاى درون كروهها \\
\hline$<* / *+$ & s/DV & $M F T / W$ & VeV & $\Delta \vee \mp / V \Lambda$ & درون آزمودنى ها: مراحل مداخله أموزشى \\
\hline \multirow[t]{2}{*}{$<+/ \cdot r t$} & $r / R$ & TTNTY & V/gV & rAT/YA & كروهها × مراحل مداخله آموزشى \\
\hline & & AT/IRT & $g \cdot / 18$ & mifv/vo & آزمودنى هاى درون كروهها × مراحل مداخله آموزشى \\
\hline
\end{tabular}




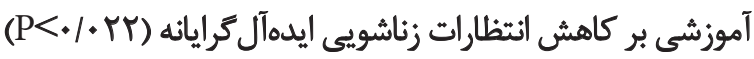
معنادار است (تصوير rآ). همان طور كه در تصوير r ملاحظه مي مدود، در كل ميانكين

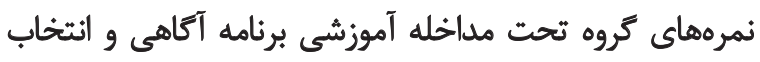

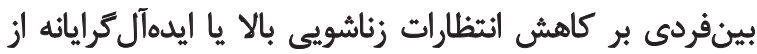

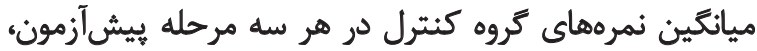

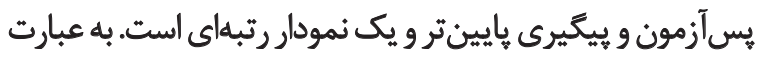

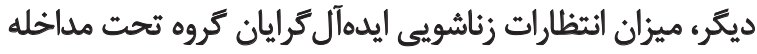

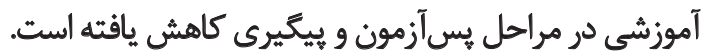

بحث

بنتايج اين يُروهش نشان داد كه آموزش آكاهى و انتخابهاي

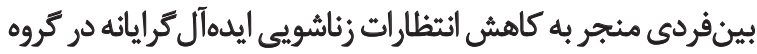

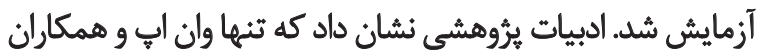

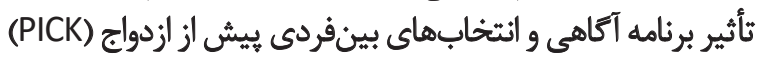

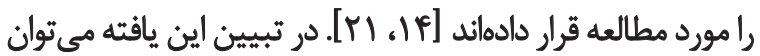

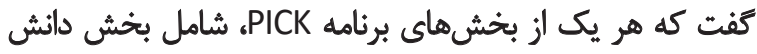

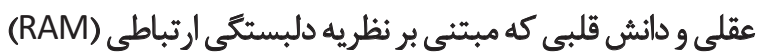
هستند در كاهش انتظارات زناشويى افراد مؤثرند.

بخش دانش عقلى شامل مؤلفه آكاهي است كه بر هـ زمينه

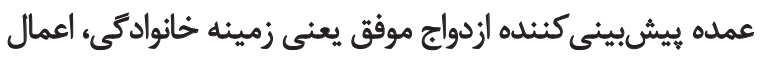

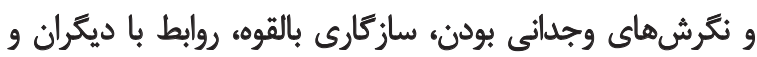

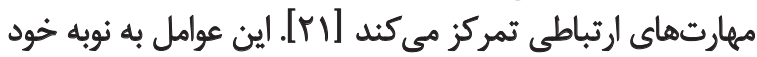

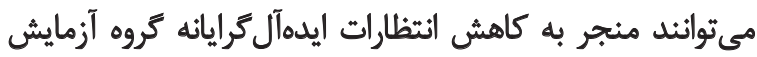

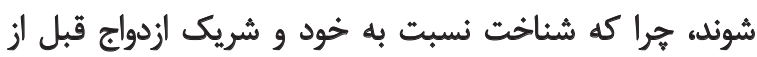

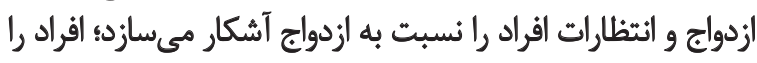

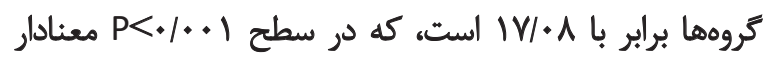

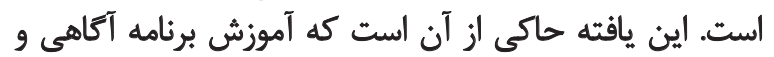
انتخابهاى بينفردى بر كاهش انتظارات زنات آناشويى ايدهآ آل كرايانه

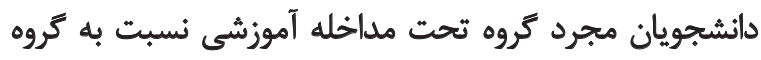
كنترل مؤثر بوده است.

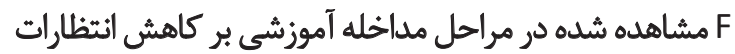

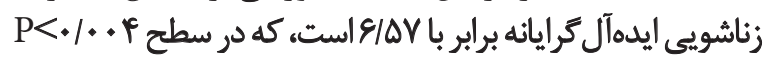

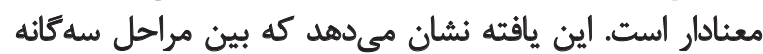

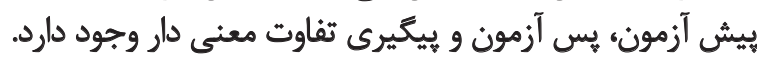

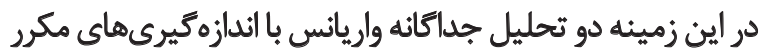

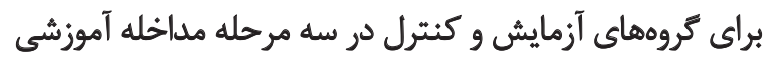

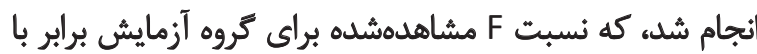

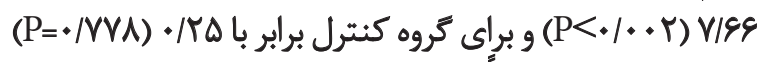

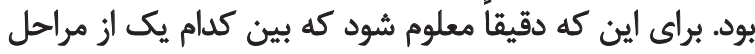

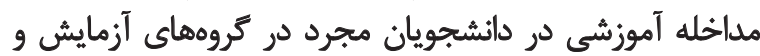

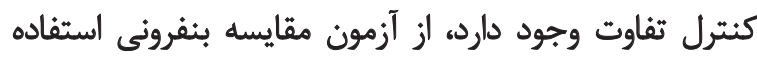

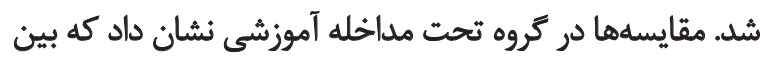

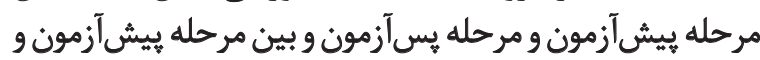

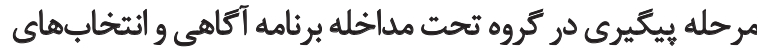

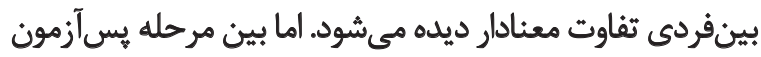

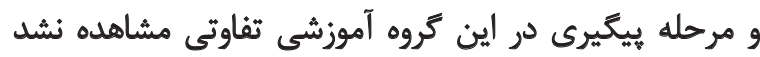

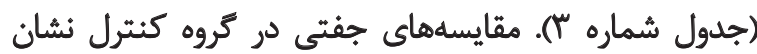

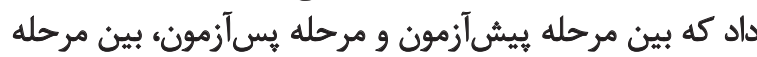

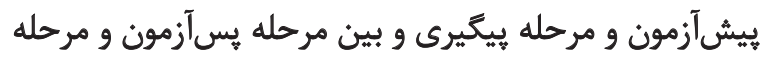

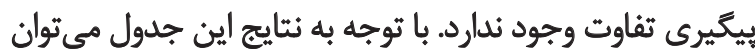

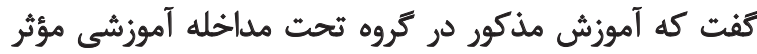

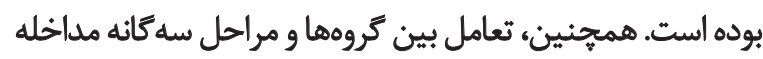

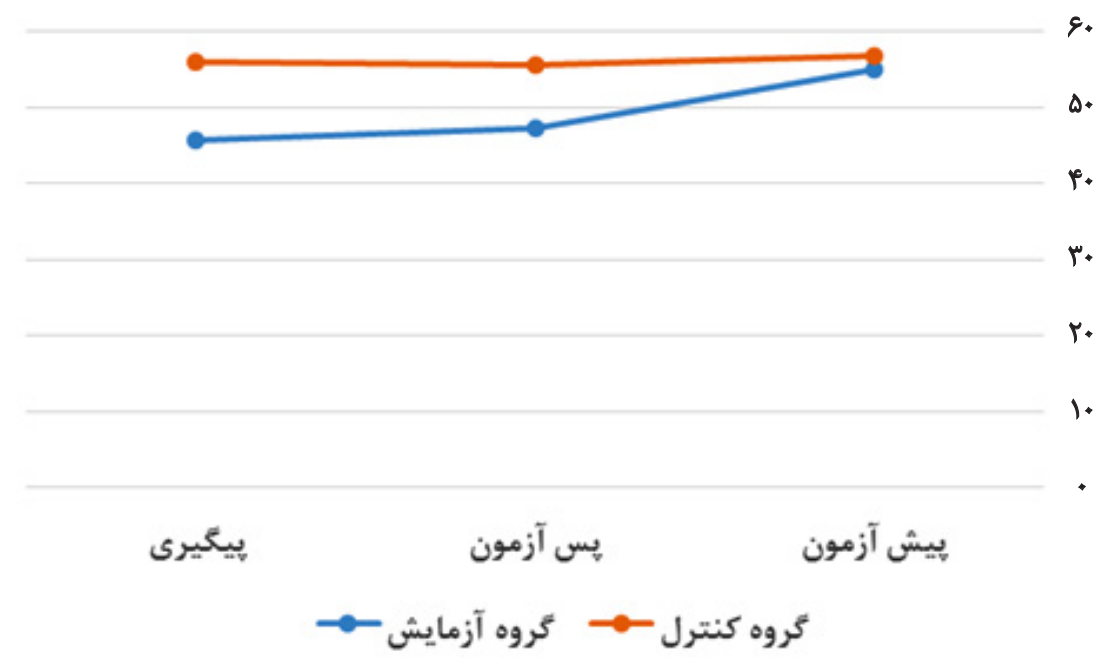

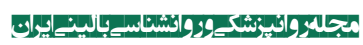

تصوير ب. تعامل كروها و مراحل سه كانه آموزشى برئامه آكاهى و ايتخابهاى بينفردى بر كاهش انتظارات زناشويى ايدهآل ترايانه. 
جدول ب. نتايج مقايسه ميانكينهاى جفتى بونفرونى مراحل آموزشى سهكانه بر كاهش انتظارات زناشويى بالا.

\begin{tabular}{|c|c|c|c|}
\hline q بحرانى q & q تفاوت ميانكين & مقايسهها & \\
\hline$P<+1+.9$ & $\Delta \Delta / \cdot \Delta-P V / \Psi T=V / N^{*}$ & نيش آزمون و يسآزمون & \\
\hline$P<\cdot 1 \cdot . r$ & $\Delta \Delta / \cdot \Delta-f \Delta / M^{H}=q / T^{\prime} \mid$ & ييش آزمون و يبيكيرى & كروه آزمايش \\
\hline$P=1$ & $P V / T 1-P \Delta / M^{\circ}=-1 / \Delta V$ & يسآزهون و ييكيرى & \\
\hline$P=1$ & $\Delta / / A P-\triangle \Delta / / A=1 / / Q$ & هيش آزمهون و يسآزمون & \\
\hline$P=1$ & $\Delta F / A P-\Delta E / 1==M^{N}$ & ييش آزمون و ييكيرى & كروه كتبرل \\
\hline$P=1$ & $\Delta F / \& \Lambda-\Delta F / 1 \cdot=-+/ R T$ & يسأزمون و ييكيرى & \\
\hline
\end{tabular}

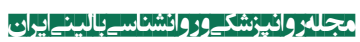

فرا مى خوانند كه خود مي توائد منجر به ناسازخارى زناشويى شود.

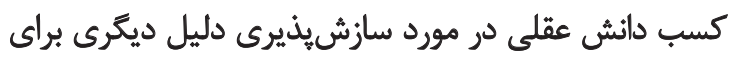

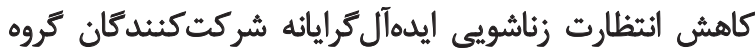

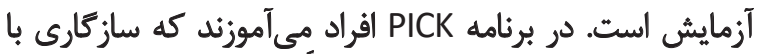

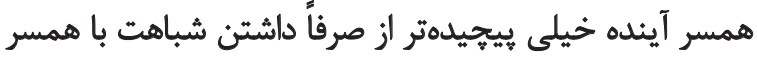

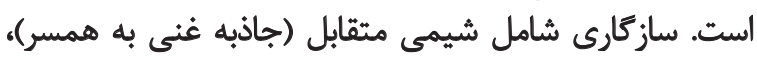

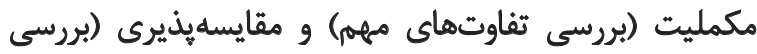

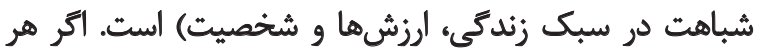

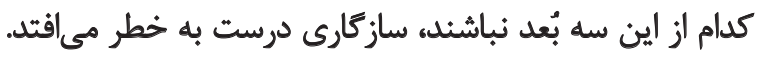

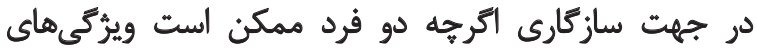

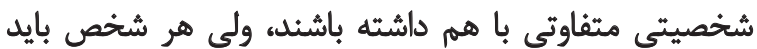

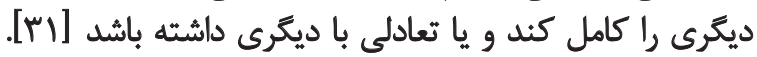

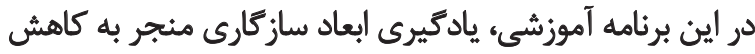

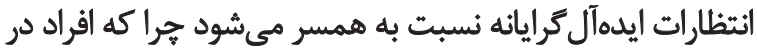

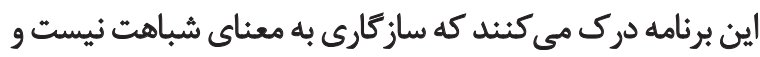

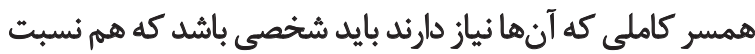

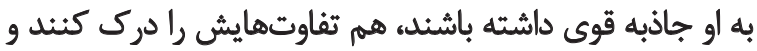

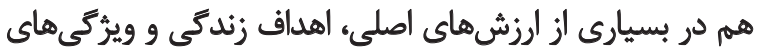

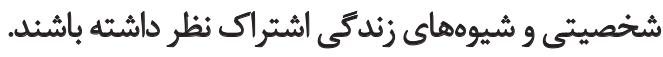
ازطرف ديكر، آكاهى و دانش عقلى در مورد مهارتهائ ارتباطي،

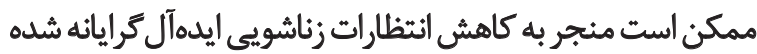

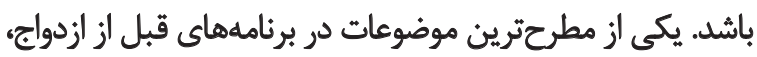

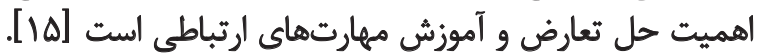

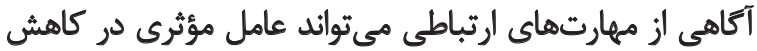

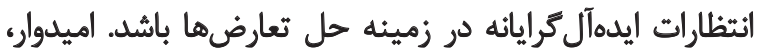

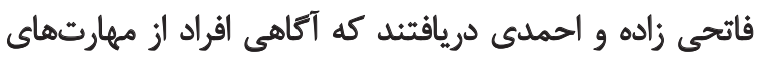

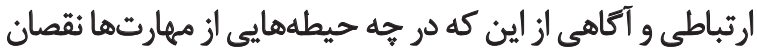

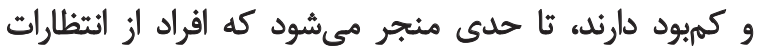

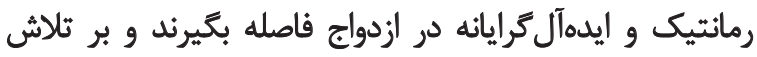

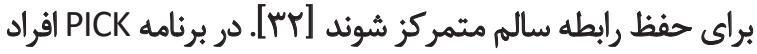

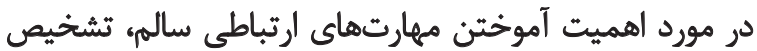

به مهارتهاي حل مسأله براى مشكلاتي كه ممكن است در آينده

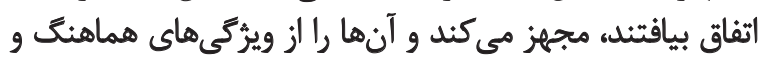

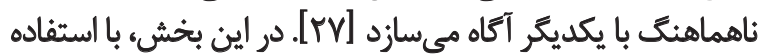

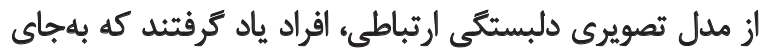

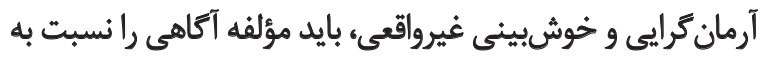

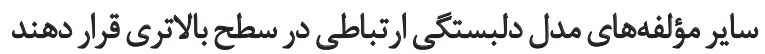

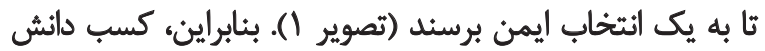

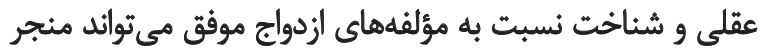

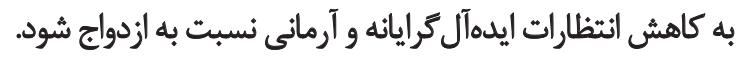
كسب دانش عقلى در مورد زمينه خانوادكى، الكوهائ خانوادكى

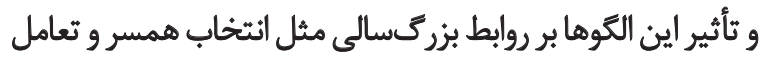

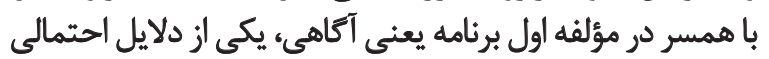

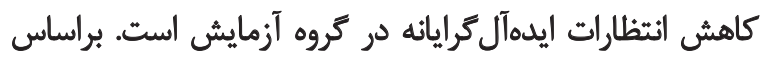

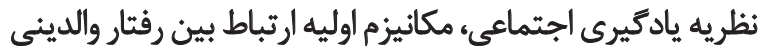

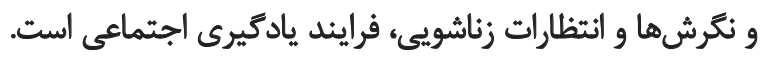

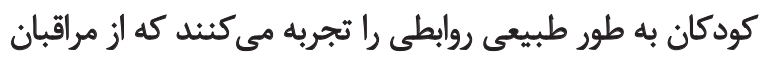

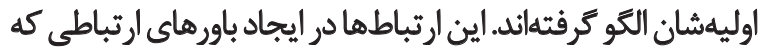

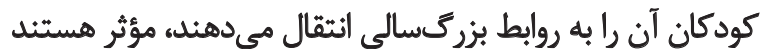

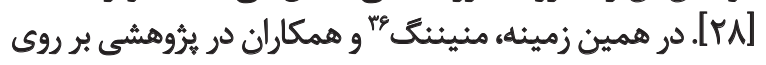

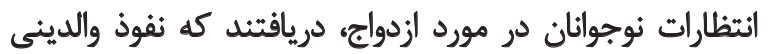

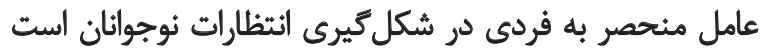

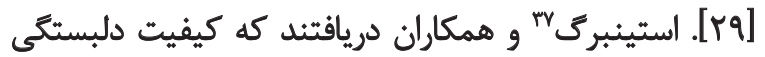

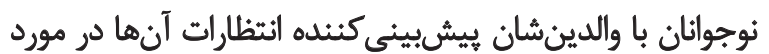

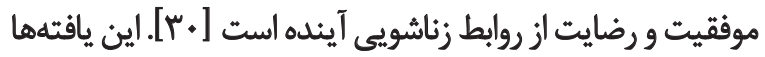

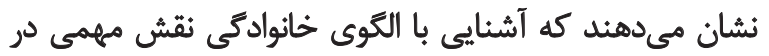

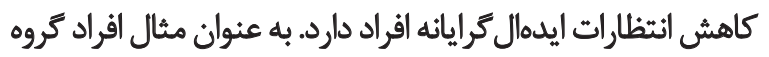

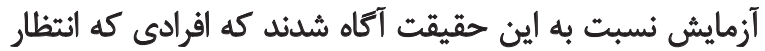

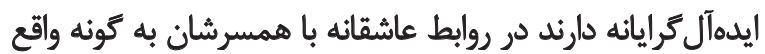

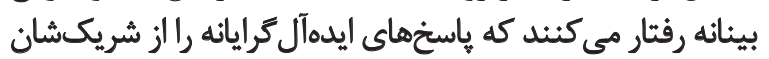


منجر به تغيير انتظارات ايدهآل كرايانه شركت كنثدكان در كروه آزمايش در مرحله ييكيرى شود.

\section{نتيجهَيَيرى}

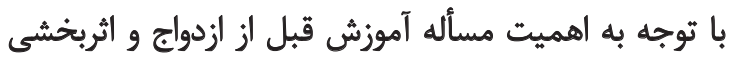

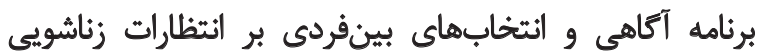

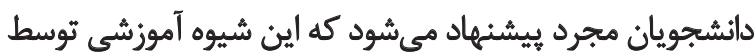

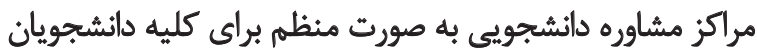

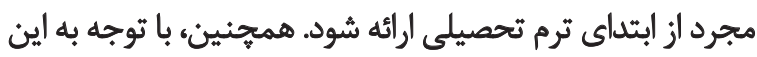

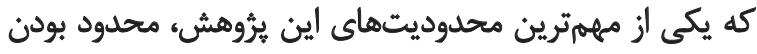

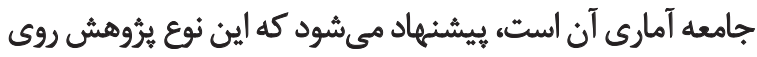

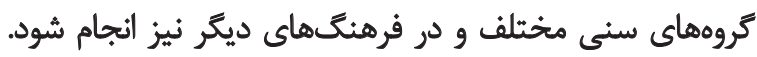

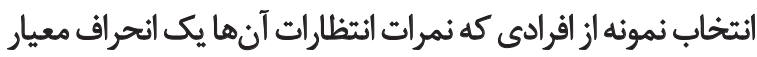

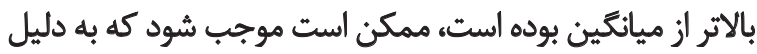

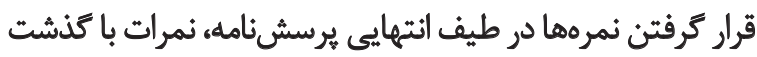

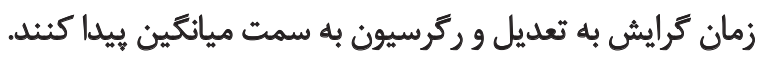

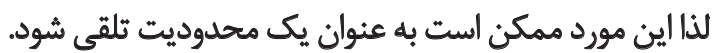

$$
\text { سياسكّزازى }
$$

از كليه دانشجوياني كه با ما در اين برؤوهش همكارى كردهانده.

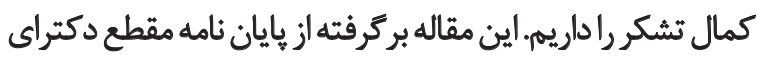

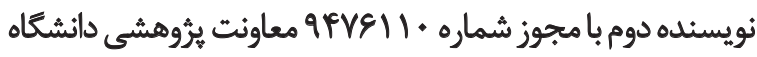

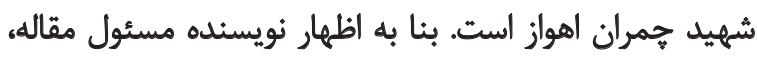
حمايت مالى از بثوهش و تعارض مناف بنا به وجود نوينداشته است.
فريب در ابراز خوده ارتباط ناهمخوان، انتظار در مورد باز بودن

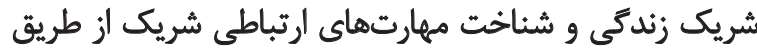

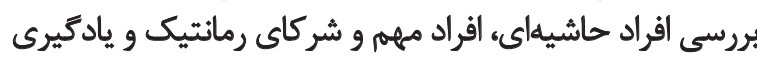

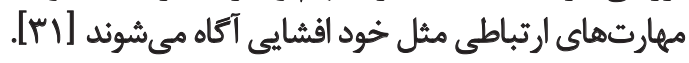

كسب دانش عقلى در مورد روابط شريك ازدواج با ديكران

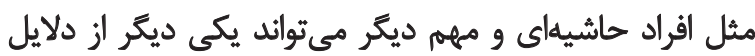

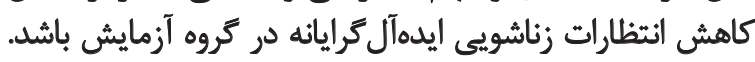

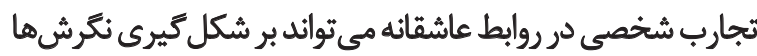

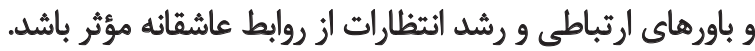

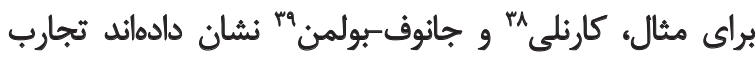

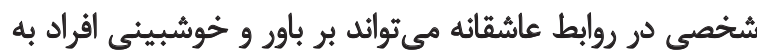

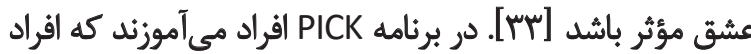

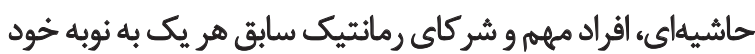

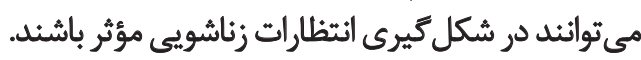

نتايج ديكر اين يثروهش نشان داد كه آموزش قبل ازئ ازئ ازدواج

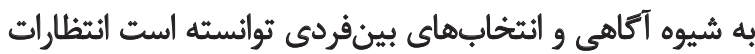

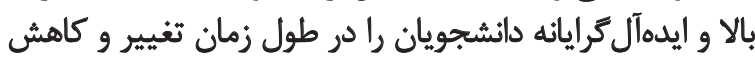

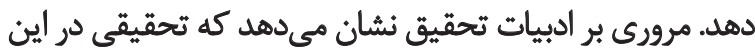

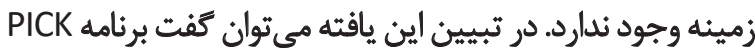

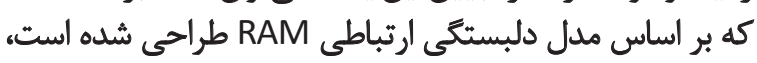

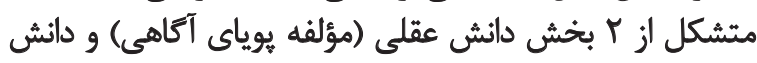

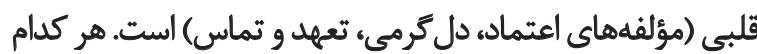

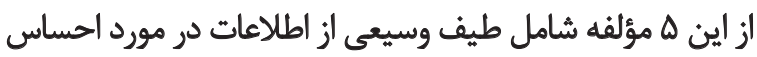

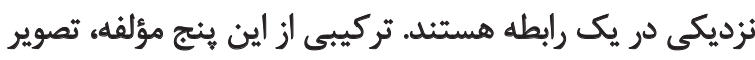

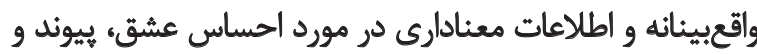

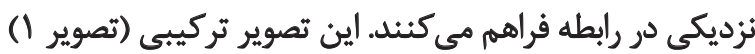

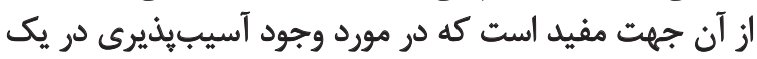

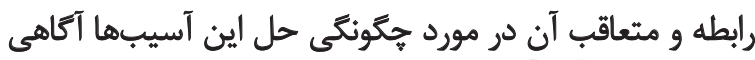

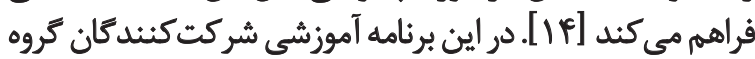

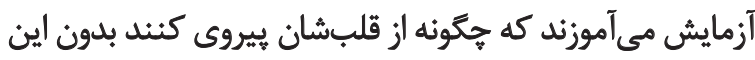

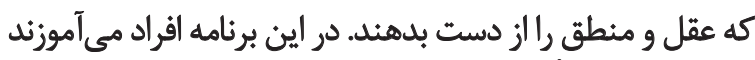

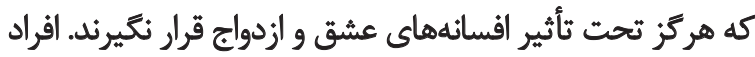

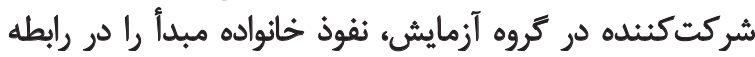

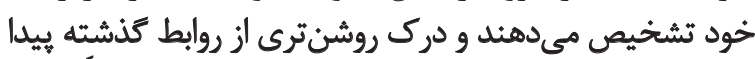

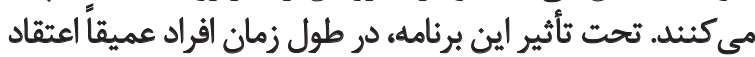

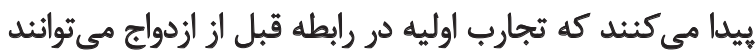

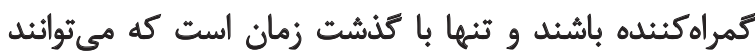

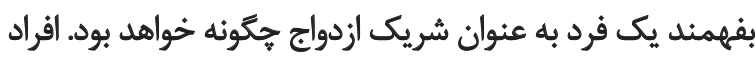

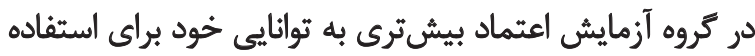

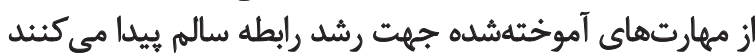

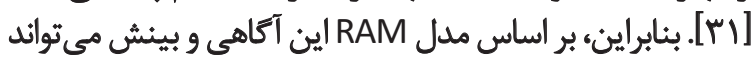




\section{References}

[1] Bradbury TN, Fincham FD, Beach S. Research on the nature and determinants of marital satisfaction: A decade in review. J Marriage Fam. 2000; 62: 964-980.

[2] Larson JH. The marriage quiz: College students' beliefs in selected myths about marriage. Fam Relat. 1988; 37: 3-11.

[3] Azzopardi C. Expectations of Marriage before \& After Marriage among Maltese Catholic Couples [dissertation]. [London]: University of East London; 2007.p. 295.

[4] Sharp EA, Ganong LH. Raising Awareness About Marital Expectations: Are Unrealistic Beliefs Changed by Integrative Teaching? Fam Relat. 2000; 49(1): 71-76.

[5] Fletcher GJ, Simpson JA, Thomas G. Ideals, perceptions, and evaluations in early relationship development. J Pers Soc Psychol. 2000; 79 (6): 933-940.

[6] Rios CM. The Relationship between Premarital Advice, Expectations and Marital Satisfaction [dissertation]. [Utah]: Utah State University; 2010. p. 67.

[7] Segrin C, Nabi RL. Does Television Viewing Cultivate Unrealistic Expectations about Marriage? J Commun. 2002; 52 (2): 247-263.

[8] Faubert K. This isn't a fairy tale: An exploration of marital expectation and coping among marriage women [dissertation]. [Miami]: Family Studies and Social Work Miami University; 2008. p. 40 .

[9] Ufholz KE. The effect of peers on marital beliefs and expectations [dissertation]. [Dayton]: The University of Dayton; 2012. p. 112.

[10] Casad BJ, Salazar MM, Macina V. The Real versus the Ideal: Predicting relationship satisfaction and well-being from endorsement of marriage myths and benevolent sexism often associated with unrealistic expectations and fairy-tale. Psychol Women Quart. 2014; 39(1): 1-11.

[11] Torppa CB. Preparing Adolescents and Young Adults for Marriage: Developing Realistic Expectations for Family Communication. Ohio: The Ohio State University; 2009. p. 1-2.

[12] Dillon HN. Family Violence and Divorce: Effects on marriage expectations [dissertation]. [Tennessee]: East Tennessee State University; 2005. p. 43.

[13] Knutson L, Olson DH. Effectiveness of PREPARE program with pre-marital couples counseling in community settings. Marriage Fam J. 2003; 6(4): 529-546.

[14] Van Epp MC. An exploration of the dating attitudes, beliefs and behavior of singles army soldiers and their perceived readiness to Mary [dissertation]. [Ohio]: The Ohio State University; 2006. p. 118.

[15] Hawkins AJ, Carroll JS, Doherty WJ, Willoughby B. A comprehensive framework for marriage education. Fam Relat. 2004; 53 : 547-558.

[16] Valiente CE, Belanger CJ, Estrada AU. Helpful and harmful expectations of premarital interventions. J Sex Marital Ther. 2002; 28(1): 71-77.

[17] Carroll JS, Doherty WJ. Evaluating the effectiveness of premarital education: A review of outcome research. Fam Relat. 2003; 52:105-118.
[18] McGeorge R, Carlson TS. Premarital education: An assessment of program efficacy. Contemp Fam Ther. 2006; 28(1):165-90.

[19] Brotherson SE, Duncan WC. Rebinding the ties that bind: Government efforts to preserve and promote marriage. Fam Relat.2004; 53: 459-468.

[20] Poley JM. A Pre-Marriage Proposal: Getting Ready for Marriage, an Adlerian Design. Master of Arts[dissertation]. [America]: Adlerian Counseling and Psychotherapy; 2011. p. 53.

[21] Van Epp MC, Futris TG, Van Epp JC, Campbell K. The impact of the PICK a partner relationship education program on single army soldiers. Fam Consumer Sci Res J. 2008; 36: 328-349.

[22] Jones GD, Nelson ES. Expectations of marriage among college students from intact and bit-intact homes. J Divorce Remarriage. 1996; 26:171-189.

[23] Nilforooshan P, Abedi A, Navidian A, Ahmadi A. Studying the factor structure, reliability, and validity of the Marriage Expectation Scale (MES). J Behav Sci. 2011; 5(1):11-19. [Persian]

[24] Tornstam L. Loneliness in marriage. J Soc Pers Relat. 1992; 9: 197-217.

[25] Wineer BJ. Statistical principles in Experimental Design. New York: McGraw-Hill.1962.

[26] Tabachnick BG, Fidell LS. Using multivariate statistics. 5th Ed. New York: Pearson. 2006; 33-46.

[27] Yilmaz T, Kalkan M. The Effects of a Premarital Relationship Enrichment Program on Relationship Satisfaction. Educ Sci. 2010; 10(3): 1911-1920.

[28] Johnson VI. The effects of intimate relationship education on relationship optimism and attitudes toward marriage [dissertation]. [Missoula]: The University of Montana; 2009.p. 84.

[29] Manning WD, Longmore MA, Giordano PC. The changing institution of marriage: Adolescents' expectation to cohabit and to marry. J Marriage Fam. 2007; 69: 559-575.

[30] 30. Steinberg SJ, Davila J, Fincham FD. Adolescent romantic expectations and experiences: Associations with perceptions about parental conflict and adolescent attachment security. J Youth Adolescence. 2006; 35: 314-329.

[31] 31. Van Epp J. How to avoid falling in love with a jerk: The foolproof way to follow your heart without losing your mind. New York: McGraw-Hill. 2007; PP. 3-15.

[32] 32. Omidvar V, Fatehizadeh M, Ahmadi A. The effect of premarital and marital expectations of students in pre-marriage in the city of Shiraz. J Fam Res. 2008; 5(18): 231-246. [Persian]

[33] 33. Carnelly KB, Janoff-Bulman R. Optimism about love relationships: General vs. specific lessons from one's personal experience. J Soc Pers Relat. 1992; 9: 5-20. 